\title{
A GIS TOOLKIT FOR AUTOMATING DESCRIPTIVE STATISTIC COMPUTATIONS FOR AIR QUALITY MODELING
}

\author{
A. Georgiou ${ }^{\mathrm{a}}, \mathrm{T}$. Kontos ${ }^{\mathrm{b}}$ \\ a Enalia Physis Environmental Research Center (ENALIA), Acropoleos 2, 2101 Aglanzia, Nicosia, Cyprus \\ ${ }^{b}$ Department of Environment, University of the Aegean University Hill, Mytilene 81100, Greece
}

Article Info:

Received: 28 August 2017

in revised form: 10 January 2018

Accepted: 10 March 2018

Available Online: 30 April 2018

\section{Keywords:}

GIS, ArcObjects, Air Quality, Athens

\section{Corresponding Author:} Georgiou Andreas

Enalia Physis Environmental Research Centre, Acropoleos 2, 2101 Aglanzia, Nicosia, Cyprus Email:

a.georgiou@enaliaphysis.org.cy

\begin{abstract}
A GIS toolset was developed to support spatial analysis functions, visualization and extraction of a variety of input variables for air quality assessment. The developed toolset allows the automated processing of large amounts of ASCII data converting to points and raster data and the examination of the correlation among them. A case study was performed in Athens basin in Greece. Using the developed GIS toolset, topographic, climatic characteristics and air pollution conditions as well correlations were derived by processing the input data. In addition, thematic maps illustrating the spatial distribution of each parameter were extracted. The developed GIS toolset greatly reduced the time and effort needed to process the GIS data, and provided a useful tool for a wide variety of environmental applications. The tool uses Arcobjects as the programming language to incorporate equations for statistical analysis in a monthly and a yearly time step. This versatile programming language allows advanced users to incorporate more complex formulations for more accurate results as detailed data is acquired to develop routines for calibration when reference data exist. Results verified the usefulness and feasibility of the developed platform.
\end{abstract}

Copyright @ 2016 GJGP-UNDIP

This open access article is distributed under a Creative Commons Attribution (CC-BY-NC-SA) 4.0 International license.

Georgiou, A., \& Kontos, T. (2018). A GIS Toolkit for Automating Descriptive Statistic Computations for Air Quality Modeling. Geoplanning: Journal of Geomatics and Planning, 5 (1), 53-62. doi:10.14710/geoplanning.5.1.53-62

\section{INTRODUCTION}

Air pollution is one of the most important environmental problems that effects megacities and urban areas from both developed and developing countries as well as entire countries and regions (Fameli \& Assimakopoulos, 2016; Henschel et al., 2015). It is directly related to the quality of life since the exposure to high levels of air pollutants is associated with a wide range of health effects. Emissions of air pollutants derive from almost all economic and societal activities (Guerreiro, Foltescu, \& de Leeuw, 2014). The principal sources are vehicular traffic, industrial activity and fossil fuel combustion in general which introduce a mixture of chemical components into the atmosphere that poses a serious environmental threat in many cities (Elbir et al., 2010; Mavrakou, Philippopoulos, \& Deligiorgi, 2012; Vienneau, de Hoogh, \& Briggs, 2009). The spatial and temporal distribution of urban air pollution caused by human activity is greatly influenced by meteorology, which defines the dispersion conditions within a specific region to a great extent.

Air pollution episodes in urban areas are found to be strongly connected with unfavourable meteorological conditions (Flocas et al., 2009; Kalabokas, Papayannis, Tsaknakis, \& Ziomas, 2012; Mavrakou et al., 2012; Sfetsos \& Vlachogiannis, 2013) and especially over coastal urban areas (Kambezidis, Weidauer, Melas, \& Ulbricht, 1998; Klemm et al., 1998; Mavrakou et al., 2012). The spatial and temporal representativeness of an air quality monitoring station is a relevant issue to describe the complex pattern of atmospheric pollution over a specific area. It is also required to provide information on air pollution for environmental and health policy, but also to act as a basic for designing and stratifying any future monitoring networks (Beelen et al., 2009). 
Geographical Information Systems (GIS) became a powerful tool for integrating and processing large amount of spatial information, performing spatial analysis and manipulating spatial outputs (España, Alcalá, Vallejos, \& Pulido-Bosch, 2011, 2013). It also provides a consistent visualization environment for displaying the input data and results of a model. This ability is very useful in any decision-making process (Georgiou \& Skarlatos, 2016; Xiaodan, Xianghao, \& Pan, 2010) and mostly in air pollution (Elbir, 2004; Elbir et al., 2010; Righini et al., 2014) which is helpful for understanding spatial patterns and dynamics (Righini et al., 2014; Sfetsos \& Vlachogiannis, 2013; Vienneau et al., 2009; Wang et al., 2009). The intrinsic ability of GIS to store, analyse and display large amounts of spatial data enables it to make a significant contribution to air pollution assessment (Desideri, Arcioni, \& Tozzi, 2008; Wang et al., 2009). Experience has been gained in the development of non-coupled GIS models programmed in several languages to address several environmental issues (Batelaan \& Smedt, 2007; Buliung \& Kanaroglou, 2006; España et al., 2011, 2013; Zhan \& Huang, 2004). A long computation time and an advanced knowledge a programming language are often more than necessary to process data series before they are introduced into a software.

ArcObjects is a component library that includes all the functions of $\operatorname{ArcGIS}^{\circledR}$ (ESRI, 2004) that permits environmental variables to be manipulated through the application of programming interfaces (Chang, 2007). The use of ArcObjects as a programming language allows access to data in their original format and thereby reduces the interactive tasks to be programmed using other programming languages (España et al., 2011). For air pollution applications, the versatility of ArcObjects as programming language has been highlighted so far only in some specific tools (Elbir et al., 2010; Qun, Yujin, \& Yuena, 2012). Thus, further steps are required to prove the versatility of ArcObjects for modelling air pollution.

The use of GIS has streamline the pre-processing and post-processing of data for environmental modelling; however, common manual methods of GIS are often tedious, time-consuming and problematic (Hirabayashi \& Kroll, 2007). Repetitive manual inputs can distract a user's concentration which may result in human errors. To overcome these problems, the present study develops from scratch a new standalone platform using ESRI ArcObjects within Visual Basic for Applications as programming language, to automate the computation of descriptive statistics for large amount of data and perform linear correlation among observed and predicted meteorological conditions and air pollutants concentrations.

A case study was then applied for Athens basin in Greece. The proposed framework comprises of a combination of already established methods and tools. Innovative aspects comprises of a unique and balanced approach among programming, practice and theory of air pollution modeling and analysis. The rest of paper is organized as follows. Section 2 is devoted to the description of the studied area and the data sources that used. In addition, this section addresses both technical and methodological details focusing on database development, assembly of the standalone platform and the origin of the adopted approaches. A presentation and illustration of the model results as applied in our case study is given in Section 3. The fourth and final section of the paper addresses issues generated by this research and documents several future research objectives.

\section{DATA AND METHODS}

Athens basin consist a complex topography system that constitutes an area of $430 \mathrm{~km}^{2}$. It is surrounded by a mountain range in the NW, NE and SE while it is open to the Aegean Sea towards the SW (Figure 1). This natural barrier entails significant difficulty in the dispersion of air masses above the basin and in addition with the local climate, have strong influence in the air pollution situations and thus the air quality of the area. The climate of the greater area of Athens is typically Mediterranean with hot dry summers and wet mild winters. The mean daily summer and winter temperatures are $25.8^{\circ} \mathrm{C}$ and $10.1^{\circ} \mathrm{C}$ respectively (Kalabokas et al., 2012). The mean wind pattern in the atmospheric boundary layer in Athens during the warmer part of the year is persisted north-easterly low of relatively high constancy winds (Repapis, Zerefos, \& Tritakis, 1977). When the north-easterly flow is weakened, a south-westerly sea-breeze circulation associated with high accumulations of air pollutants and eventually severe photochemical pollution episodes (Kalabokas et al., 2012; Kambezidis et al., 1998). The meteorological conditions prevailing in urban areas with the intense primary pollutant emissions might deteriorate the air quality and lead to serious 
pollution episodes (Flocas et al., 2009; Mavrakou et al., 2012; Papanastasiou \& Melas, 2009; Sfetsos \& Vlachogiannis, 2013).

Table 1. Characteristics of observational stations

\begin{tabular}{|c|c|c|c|c|c|}
\hline No & Name & Code & $\begin{array}{c}\text { Elevation } \\
(\mathrm{m})\end{array}$ & Land-use & Parameter \\
\hline 1 & Athinas & ATH & 100 & Urban Traffic & $\mathrm{SO}_{2}, \mathrm{NO}_{x}, \mathrm{CO}, \mathrm{O}_{3}$ \\
\hline 2 & Aristotelous & ARI & 95 & Urban Traffic & $\mathrm{SO}_{2}, \mathrm{NO}_{x}, \mathrm{PM} 10$ \\
\hline 3 & Geoponiki & GEO & 50 & Suburban Traffic & $\mathrm{SO}_{2}, \mathrm{NO}_{x}, \mathrm{CO}, \mathrm{O}_{3}, \mathrm{RH}, \mathrm{Ta}, \mathrm{WSp}, \mathrm{WDr}$ \\
\hline 4 & Liosia & LIO & 165 & Suburban Background & $\mathrm{SO}_{2}, \mathrm{NO}_{x}, \mathrm{O}_{3}, \mathrm{RH}, \mathrm{Ta}, \mathrm{WSp}, \mathrm{WDr}$ \\
\hline 5 & Lykovrisi & LYK & 210 & Suburban traffic & $\mathrm{NO}_{x}, \mathrm{CO}, \mathrm{O}_{3}, \mathrm{PM}_{10}, \mathrm{RH}, \mathrm{Ta}, \mathrm{WSp}, \mathrm{WDr}$ \\
\hline 6 & Marousi & MAR & 145 & Urban Traffic & $\mathrm{SO}_{2}, \mathrm{NO}_{x}, \mathrm{CO}, \mathrm{O}_{3}, \mathrm{PM}_{10}, \mathrm{RH}, \mathrm{Ta}, \mathrm{WSp}, \mathrm{WDr}$ \\
\hline 7 & Nea Smyrni & SMY & 50 & Urban Background & $\mathrm{SO}_{2}, \mathrm{NO}_{x}, \mathrm{CO}, \mathrm{O}_{3}$ \\
\hline 8 & Patision & PAT & 105 & Urban Traffic & $\mathrm{SO}_{2}, \mathrm{NO}_{x}, \mathrm{CO}, \mathrm{O}_{3}, \mathrm{RH}, \mathrm{Ta}, \mathrm{WSp}, \mathrm{WDr}$ \\
\hline 9 & Pireas & PIR & 20 & Urban Traffic & $\mathrm{SO}_{2}, \mathrm{NO}_{x}, \mathrm{CO}, \mathrm{O}_{3}, \mathrm{PM}_{10}$ \\
\hline 10 & Peristeri & PER & 80 & Urban Background & $\mathrm{SO}_{2}, \mathrm{NO}_{x}, \mathrm{CO}, \mathrm{O}_{3}$ \\
\hline 11 & Agia Paraskevi & AGP & 290 & Suburban Background & $\mathrm{SO}_{2}, \mathrm{NO}_{x}, \mathrm{O}_{3}, \mathrm{PM}_{10}, \mathrm{RH}, \mathrm{Ta}, \mathrm{WSp}, \mathrm{WDr}$ \\
\hline 12 & Galatsi & GAL & 145 & Urban Background & $\mathrm{SO}_{2}, \mathrm{NO}_{x}, \mathrm{O}_{3}, \mathrm{RH}, \mathrm{Ta}, \mathrm{WSp}, \mathrm{WDr}$ \\
\hline 13 & Goudi & GOU & 155 & Urban Traffic & $\mathrm{NO}_{x}, \mathrm{O}_{3}$ \\
\hline 14 & Eleysina & ELE & 20 & Suburban traffic & $\mathrm{SO}_{2}, \mathrm{NO}_{\mathrm{x}}$ \\
\hline 15 & Zografou & PAN & 245 & Suburban Background & $\mathrm{SO}_{2}, \mathrm{NO}_{x}, \mathrm{O}_{3}, \mathrm{PM}_{10}$ \\
\hline 16 & Thrakomakedones & THR & 550 & Suburban Background & $\mathrm{NO}_{x}, \mathrm{O}_{3}, \mathrm{PM}_{10}, \mathrm{RH}, \mathrm{Ta}, \mathrm{WSp}, \mathrm{WDr}$ \\
\hline
\end{tabular}

Hourly average concentration data of air pollutants $\left(\mathrm{SO}_{2}, \mathrm{NO}_{\mathrm{x}}, \mathrm{CO}, \mathrm{O}_{3}\right.$ and $\left.\mathrm{PM}_{10}\right)$ covering a year period is the starting data of this study, available from both observational ground stations of the air quality network and a forecast model system under the supervision of the Air Pollution and Noise Control Division of the Hellenic Ministry of Environment. The process of stations data selection was based on the criterion of a representative, in terms of urban and suburban, distribution of the measuring stations as well as on the condition of the availability of an adequate number of temporally common samples. The stations that fulfilled the criteria for selection were: (1) Agia Paraskevi (AGP), (2) Athinas (ATH), (3) Aristotelous (ARI), (4) Geoponiki (GEO), (5) Galatsi (GAL), (6) Goudi (GOU), (7) Eleysina (ELE), (8) Zografou (PAN), (9) Thrakomakedones (THR), (10) Liosia (LIO), (11) Lykovrisi (LYK), (12) Marousi (MAR), (13) Nea Smyrni (SMY), (14) Patision (PAT), (15) Pireas (PIR) and (16) Peristeri (PER) (Figure 1). The meteorological variables of Relative Humidity (RH), Air Temperature (Ta), Wind Speed (Wsp) and Wind Direction (Wdr) over the respective period of time, besides the forecast model, were obtained as well from the following stations: Geoponiki, Liosia, Lykovrisi, Marousi, Patision, Agias Paraskevis, Galatsi and Thrakomakedones. In Table 1, the characteristics of each observational station with the respect measured parameter are summarized.

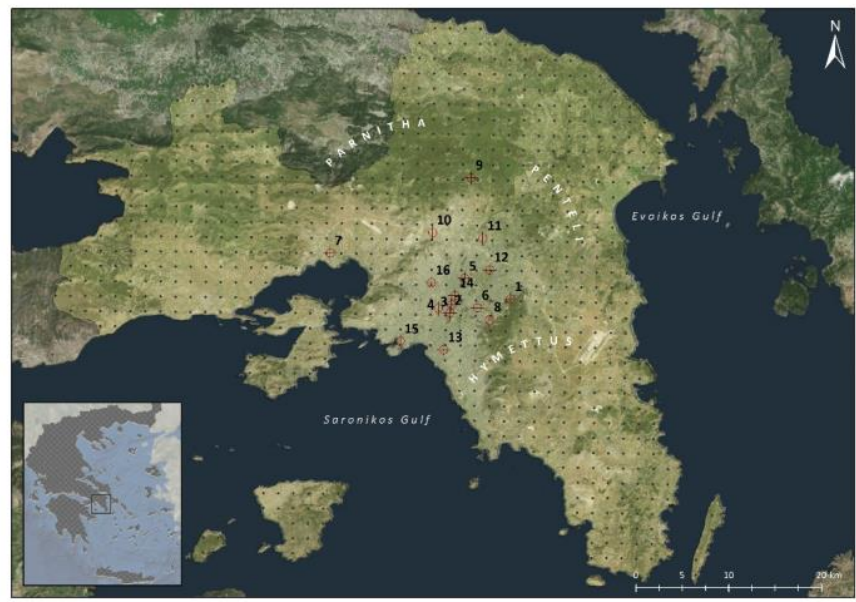

Figure 1. Study area of Athens basin including forecast model grid (black dots) and observational stations (red points) 
The forecast model, covers an area of $2.2 \times 10^{4} \mathrm{~km}^{2}$ including the study area, using a $2 \mathrm{~km}$ grid points (Figure 1) from where each point calculates air pollutants concentrations and meteorological conditions parameter values. Wind speed is calculated in $10 \mathrm{~m}$ above sea level while temperature at $2 \mathrm{~m}$ above sea level. Both data sources gathered from observational ground stations and forecast model system respectively, were in American Standard Code for Information Interchange (ASCII) format.

\section{RESULTS AND DISCUSSION}

\subsection{System characteristics and implementation}

The developed platform serve as an analytic interface to the object-relational spatial database. Air pollutants and meteorological conditions patterns and correlations among them can be explored using a variety of approaches originating in spatial statistics, computational geometry and geography. Development of this standalone platform involved programming of ESRI ArcObjects using Visual Basic for Applications (VBA). ArcObjects is an extensive set of Component Object Model (COM) compliant objects that facilitate customization of ArcGIS or the development of standalone platforms to meet the demands of specific applications (Buliung \& Kanaroglou, 2006; Zeiler, 2001). ArcObjects can also be extended using any COMcompliant programming language. The end result is a powerful GIS-based development environment that encourages interoperability and re-use of software components (Buliung \& Kanaroglou, 2006; Zeiler, 2001). The developed platform it is an open source standalone application with the only limitation to access to its all components and tools, is to have preinstalled a licensed ArcGIS ${ }^{\mathrm{TM}}$ software and VBA. In addition, the used geodatabase which is linked to the platform, developed with the aid of the Unified Modeling Language (UML) notation and the Microsoft Visio visual modeling tool (Taylor, 1997). The developed system gives robust state-of-the-art performance on the analysis and visualization of massive volume of data. It has also a user friendly navigate environment with the capability to be easily adjusted to address any needs through VBA programming.

Figure 2 provides a schematic diagram of the developed GIS based platform with the operational functions that can be performed through it. The main idea for the developed platform, is to give the opportunity to the user to choose the operations that wants to run by navigating first through the flexible designed geodatabase within an easy interface, and selecting the preferable parameter and time step. Formats for data in this figure are presented with different symbols and are denoted at the bottom of the figure. Double-lined rectangles represent the three main functions that developed through the platform: the Descriptive Statistics Calculation function, the Correlation among the parameters function and the Visualization of parameters function.

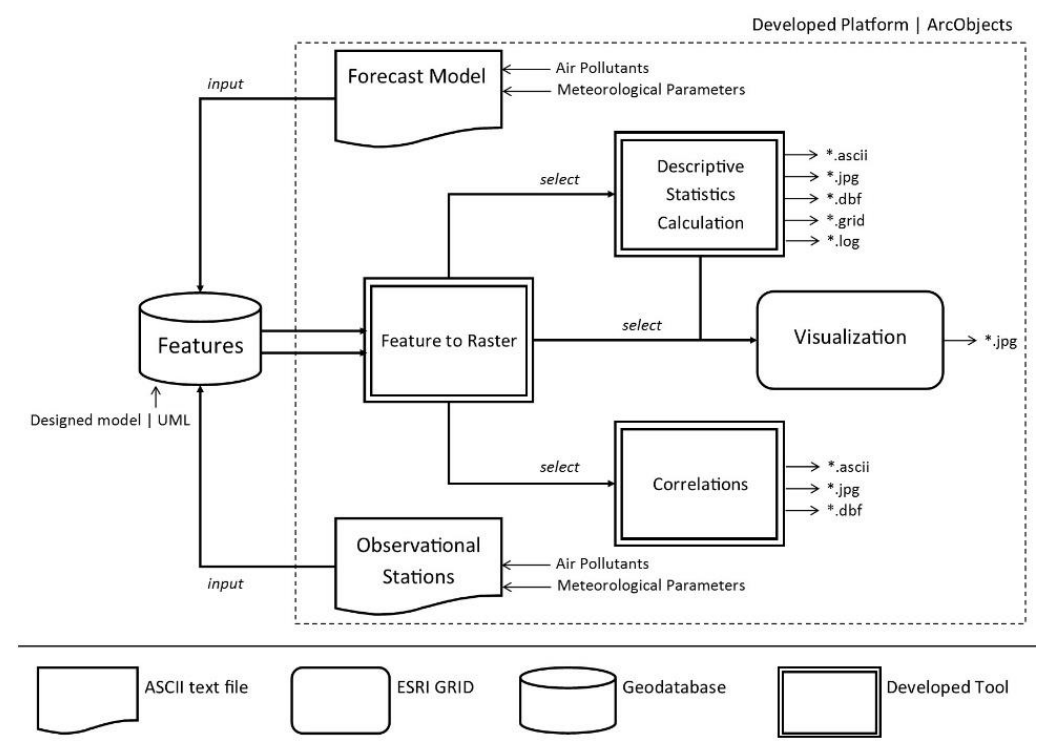

Figure 2. Schematic diagram of processes performed with the developed tool 
Descriptive statistics are derived by overlaying raster data representing any parameter onto area of interest defined by a raster mask, and computing statistics of values assigned in grids that fall within the area. This function provides an efficient way of analysis within a large amount of raster data and allow to user to indicate which parameter should be analyzed. Calculated statistics are stored mainly in an output table along with the identification of the corresponding parameter in a dBASE format, that make it easily readable by several spreadsheet packages. In addition, to the output a tables a log file is also created that indicates any errors within the batch processing.

Referring to the geodatabase, the designed model has been specified to logically separate geographic and non-geographic content (Figure 3). Boxes are classes that after implementation become tables in the object relational database while line segments connecting classes and identify the relationship among them that can be used to navigate through database content. In addition, all attributes have been defined on all classes. The approach of database development adopted, hold both conceptual and software development advantages. First, classes and relationship descriptions have detailed programmed directly into the design model. These descriptions include spatial characteristics of the data, information sources and contacts, and detailed field descriptions. The designed model serves as both structural diagram of database content, and as a rich metadata repository. Second, using relationships programmed between classes during design, offers the ability to operationalize object collaboration in support of query, retrieval and assembly of individual and household level activity patterns. Thus, the approach to data management supports rapid development of exploratory tools. Third, the all database revision process is enhanced by the presence of the original data model and the visual modeling environment that characterize object-oriented approaches to system design. Finally, the use of a standardized notation for database design, coupled with detailed class and relationship descriptions, potentially reduces dependence of future researchers on the experience and knowledge of the original database programmer (Buliung \& Kanaroglou, 2006).

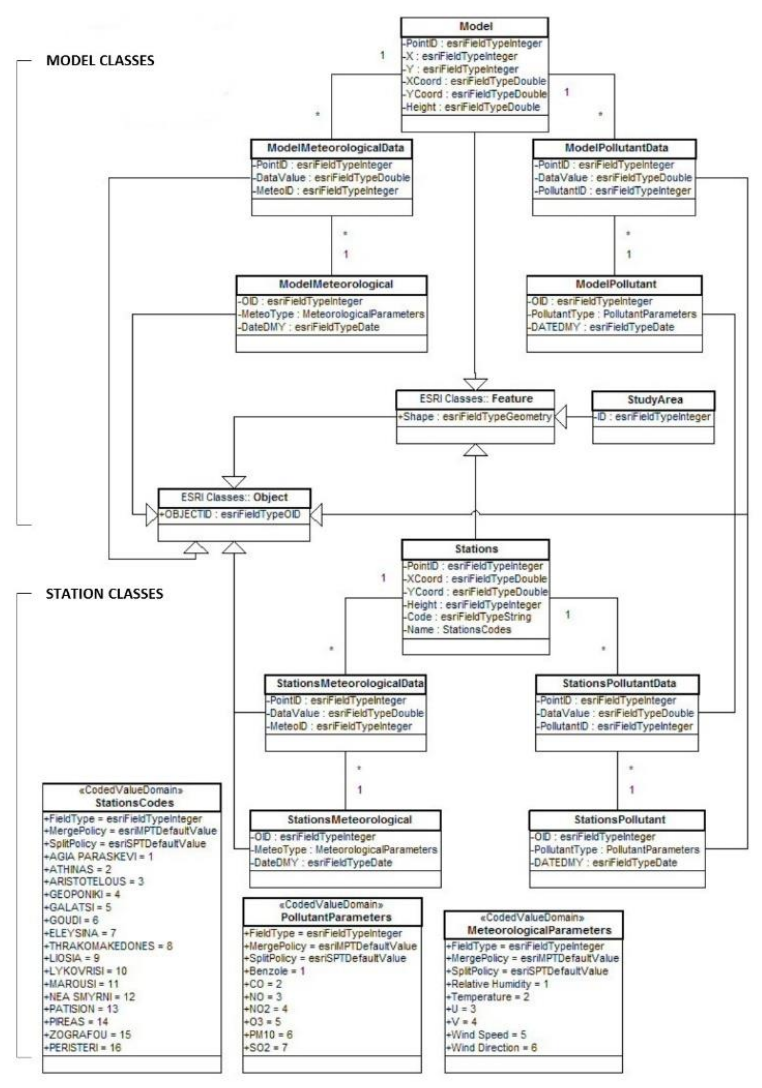

Figure 3. Developed database schema 
The friendly use interface of the developed platform (Figure 4) provides a fast and easy navigation through the developed geodatabase. The user it is able to add data to the database, convert feature points to the preferable format, visualize and edit them to the display window through a variety of useful tools that provided. Figure 4 (A) presents the main window of the developed platform where: (1) is the main toolbar where the user can navigate through the geodatabase and make conversions; (2) is the tool set for navigating at the extend window; (3) provides the ability to select available converted parameters to correlate, visualize and extract their statistics information, and; (4) is the extend window where the preferable parameter is visualized. Figure 4 (B) presents a selected parameter as visualized at the extent window. Pre-selected color ramps depending the parameter are used for the visualization taking into consideration the spatial statistics (minimum, maximum and standard deviation) of the raster file.
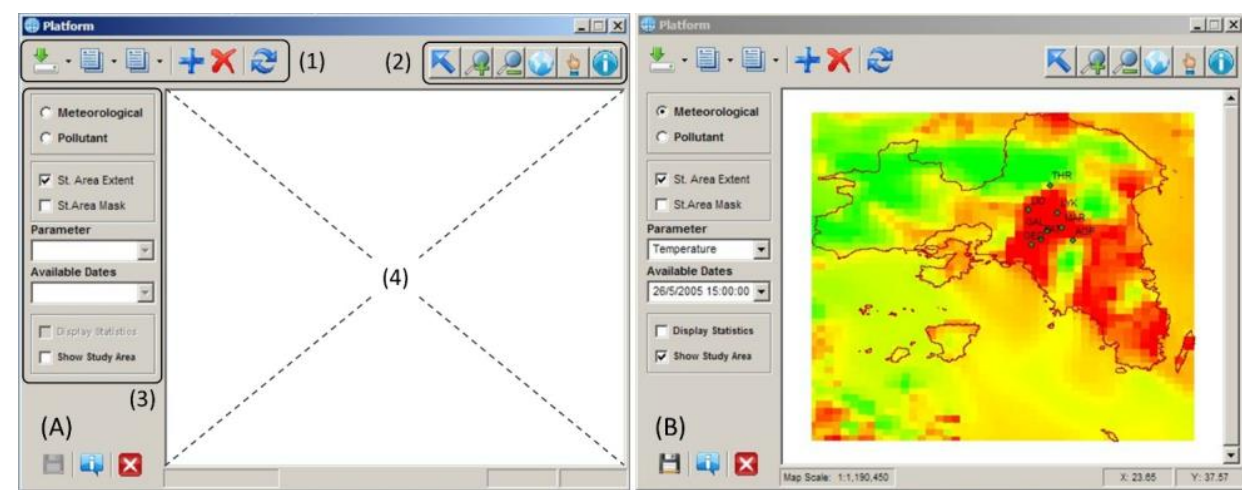

Figure 4. Screenshots of the developed platform. (A) Main window; (B) Visualization of a selected parameter

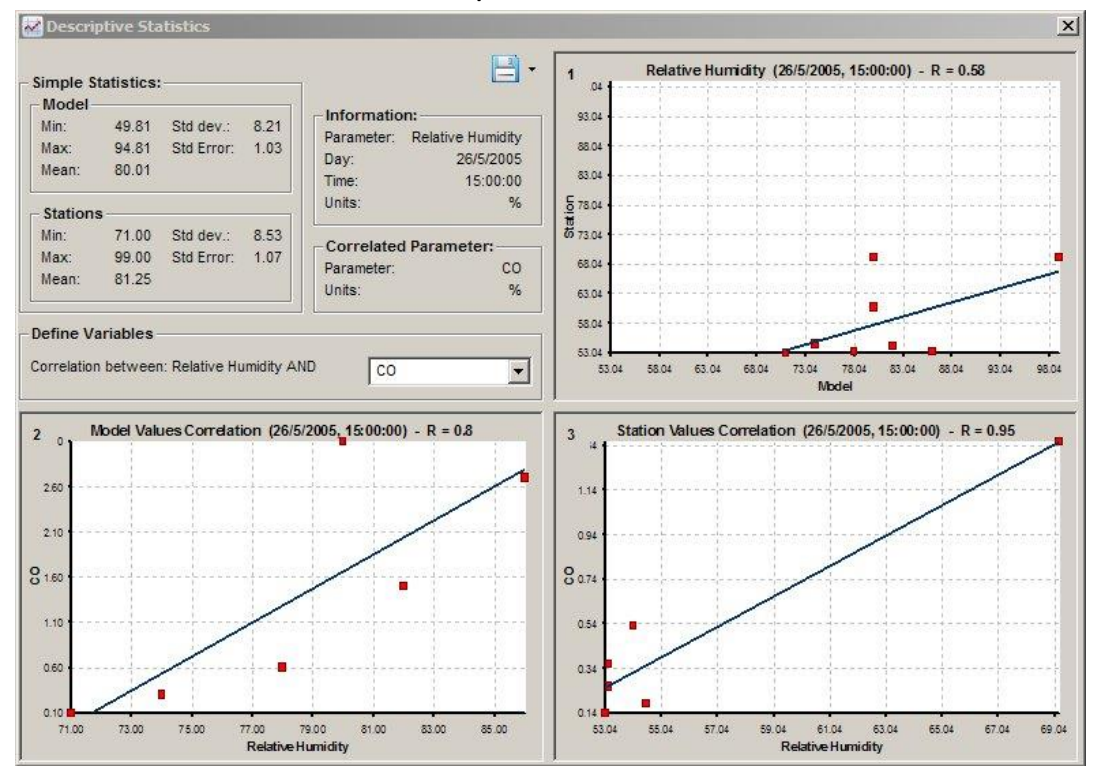

Figure 5. Screenshot of analysis window

Figure 5 presents the analysis window where the information about descriptive statistics of the selected parameter (from the main window) are presented. In addition, the user has the ability to choose a second parameter to correlate with from a drop down list that includes both air pollutants and meteorological parameters. Statistical correlation of pollutant concentrations with meteorological variables have been assessed through linear regression both for observational stations and forecast model.

\subsection{System Application to Case Study}

Application of the developed GIS based standalone platform to the case study indicates that the batch processing of the statistics calculation greatly reduced time and effort to process a large amount of both ASCII and raster data. Manual operation for the examination and correlation of data from different sources, would involve the specifying of the database from ASCll files, converting to raster data, running the commands to ArcGIS to calculate descriptive statistics and performing correlations, copying the calculate 
statistics to an output table and producing thematic maps. To process a large amount of data, these manual operations need to be performed repeatedly, which may potentially produce human errors. Due to a lack of traceability for those manual operations, errors are difficult to detect. However, the developed toolset has a capability to trace data and procedures. Sources for human error reside only in the examination of the raw data, in the creation of the parameter files and inputs to the user interfaces. Those possible errors can be detected in the process logging and attribute naming. In addition, upon the creation of raster and features, statistics can be easily calculated and thematic maps can be illustrated with no changes to the original parameter files.

Table 2. Results of the correlation analysis as derived from the developed platform;

[A] Meteorological parameters; [B] Air pollutants

\begin{tabular}{|c|c|c|c|c|c|c|c|c|c|c|c|c|}
\hline \multirow{2}{*}{$\begin{array}{l}{[\mathrm{A}]} \\
\text { Parameter }\end{array}$} & \multicolumn{6}{|c|}{ Observational Stations } & \multicolumn{6}{|c|}{ Forecast Model } \\
\hline & Time & Min & Max & Mean & Std Dev & Std Error & Min & Max & Mean & Std Dev & Std Error & $\mathbf{R}$ \\
\hline \multirow[t]{2}{*}{ Temperature } & 03:00 & 13.2 & 21.1 & 18.2 & 2.4 & 0.3 & 11.3 & 18.9 & 16.7 & 1.6 & 0.2 & 0.86 \\
\hline & $15: 00$ & 13.6 & 21.9 & 19.3 & 2.6 & 0.3 & 12.5 & 25.2 & 18.8 & 1.7 & 0.2 & 0.59 \\
\hline Relative & 03:00 & 70.0 & 89.0 & 77.0 & 5.5 & 0.5 & 80.0 & 100.0 & 89.0 & 4.2 & 0.5 & 0.38 \\
\hline Humidity & $15: 00$ & 71.0 & 99.0 & 81.0 & 8.5 & 1.1 & 50.0 & 94.0 & 80.0 & 8.2 & 1.0 & 0.58 \\
\hline \multirow[t]{2}{*}{ Wind Speed } & 03:00 & 0.9 & 5.8 & 2.4 & 1.7 & 0.2 & 0.4 & 12.5 & 4.3 & 2.1 & 0.2 & 0.85 \\
\hline & $15: 00$ & 2.4 & 5.2 & 3.9 & 2.1 & 0.2 & 0.5 & 12.0 & 6.3 & 2.1 & 0.2 & 0.21 \\
\hline \multirow{2}{*}{$\begin{array}{l}\text { Wind } \\
\text { Direction }\end{array}$} & 03:00 & SE & NE & SW & ---- & ---- & 0.7 & W & SW & ---- & ---- & 0.35 \\
\hline & $15: 00$ & NE & SW & NE & ---- & ---- & 0.6 & W & SW & ---- & ---- & 0.22 \\
\hline [B] & \multicolumn{6}{|c|}{ Observational Stations } & \multicolumn{6}{|c|}{ Forecast Model } \\
\hline Parameter & Time & Min & Max & Mean & Std Dev & Std Error & Min & Max & Mean & Std Dev & Std Error & $\mathbf{R}$ \\
\hline \multirow[t]{2}{*}{$\mathrm{CO}\left(\mathrm{mg} / \mathrm{m}^{3}\right)$} & 03:00 & 0.1 & 0.8 & 0.4 & 0.2 & 0.1 & 0.1 & 0.3 & 0.1 & 0.1 & 0.0 & 0.4 \\
\hline & $15: 00$ & 0.1 & 3.1 & 1.4 & 1.3 & 0.2 & 0.1 & 1.4 & 0.1 & 0.1 & 0.1 & 0.7 \\
\hline \multirow[t]{2}{*}{$\mathrm{NO}\left(\mathrm{mg} / \mathrm{m}^{3}\right)$} & 03:00 & ---- & ---- & ---- & ---- & ---- & 0.0 & 0.0 & 0.0 & 0.0 & ---- & ---- \\
\hline & $15: 00$ & 1.0 & 83.0 & 18.0 & 24.9 & 1.6 & 0.1 & 70.6 & 1.3 & 3.6 & 0.2 & 0.4 \\
\hline \multirow[t]{2}{*}{$\mathrm{NO}_{2}\left(\mathrm{mg} / \mathrm{m}^{3}\right)$} & 03:00 & 3.0 & 57.0 & 18.6 & 14.7 & 0.9 & 0.0 & 40.8 & 2.5 & 4.4 & 0.3 & 0.5 \\
\hline & $15: 00$ & 3.0 & 78.0 & 32.1 & 23.7 & 1.6 & 0.1 & 69.2 & 4.1 & 6.3 & 0.4 & 0.7 \\
\hline \multirow[t]{2}{*}{$\mathrm{SO}_{2}\left(\mathrm{mg} / \mathrm{m}^{3}\right)$} & 03:00 & 2.0 & 26.0 & 6.8 & 7.5 & 0.7 & 0.0 & 97.2 & 4.1 & 8.7 & 0.8 & 0.1 \\
\hline & $15: 00$ & 2.0 & 25.0 & 6.4 & 7.4 & 0.7 & 0.1 & 88.1 & 2.6 & 4.6 & 0.4 & 0.1 \\
\hline \multirow{2}{*}{$\mathrm{O}_{3}\left(\mathrm{mg} / \mathrm{m}^{3}\right)$} & 03:00 & 22.0 & 116.0 & 72.6 & 25.3 & 1.8 & 12.5 & 80.1 & 64.7 & 9.2 & 0.6 & 0.5 \\
\hline & $15: 00$ & 13.0 & 87.0 & 53.6 & 24.5 & 1.9 & 23.3 & 91.6 & 76.4 & 5.9 & 0.4 & 0.7 \\
\hline \multirow{2}{*}{$\begin{array}{l}\mathrm{PM}_{10} \\
\left(\mathrm{mg} / \mathrm{m}^{3}\right)\end{array}$} & 03:00 & 25.0 & 43.0 & 31.3 & 7.5 & 1.1 & 1.9 & 94.7 & 11.3 & 9.9 & 1.4 & 0.3 \\
\hline & $15: 00$ & 19.0 & 162.0 & 56.7 & 48.0 & 6.9 & 0.7 & 88.9 & 11.1 & 9.3 & 1.3 & 0.5 \\
\hline
\end{tabular}

Table 2 presents a preliminary set of results as derived from the proposed analysis, regarding the correlation among data from observational ground stations and a forecast model system. As it is shown, a strong correlation it is presented in most of the data for both meteorological and air pollutants parameters. In some cases although, a slightly and even considerably overestimation or underestimation of the forecasted model is presented compared the data derived from the observational stations. The strongest correlation is presented at parameters of Temperature, Wind Speed and 03 with $\mathrm{R}>74$, while for all air pollutants parameters the forecast model it is systematically underestimating.

In Figure 6 and Figure 7, a set of maps are presented as extracted from the save function of the developed platform. Each parameter visualized and its spatial distribution is illustrated according the estimate values of the forecast model in comparison with the observed measurements of the ground stations. All presented parameters where from the afternoon observation of 15:00. 


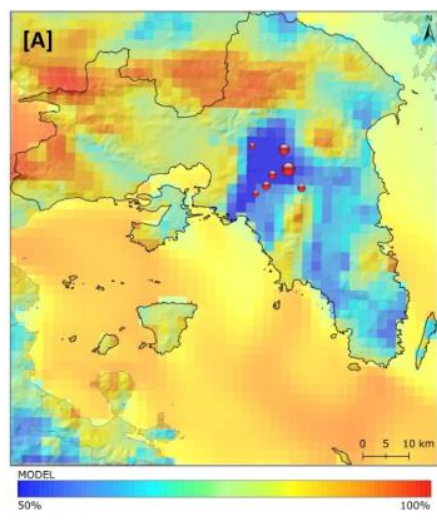

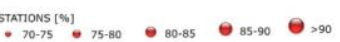

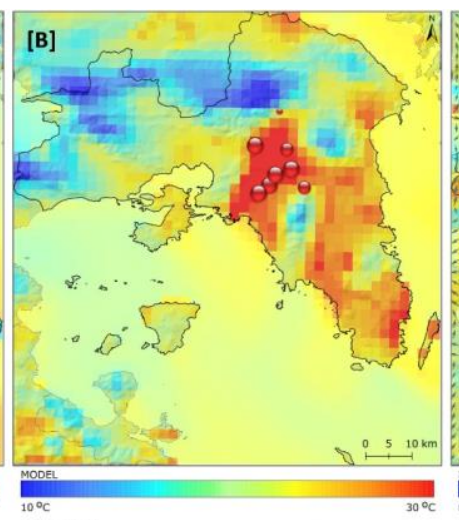

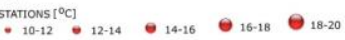

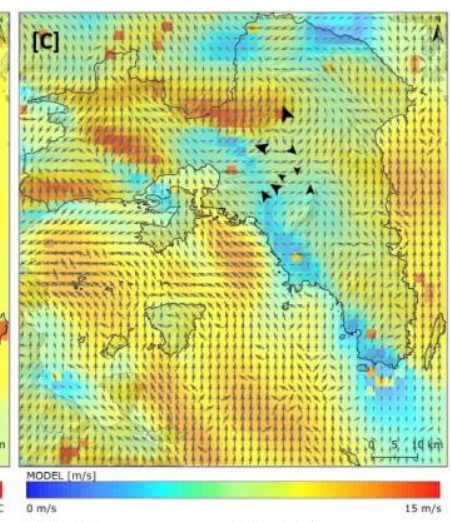

MOOEL $[m / s]$

Figure 6. Visualization and spatial distribution of meteorological parameters from both model and stations observations; [A] Relative humidity; [B] Temperature; [C] Wind Speed and Wind Direction
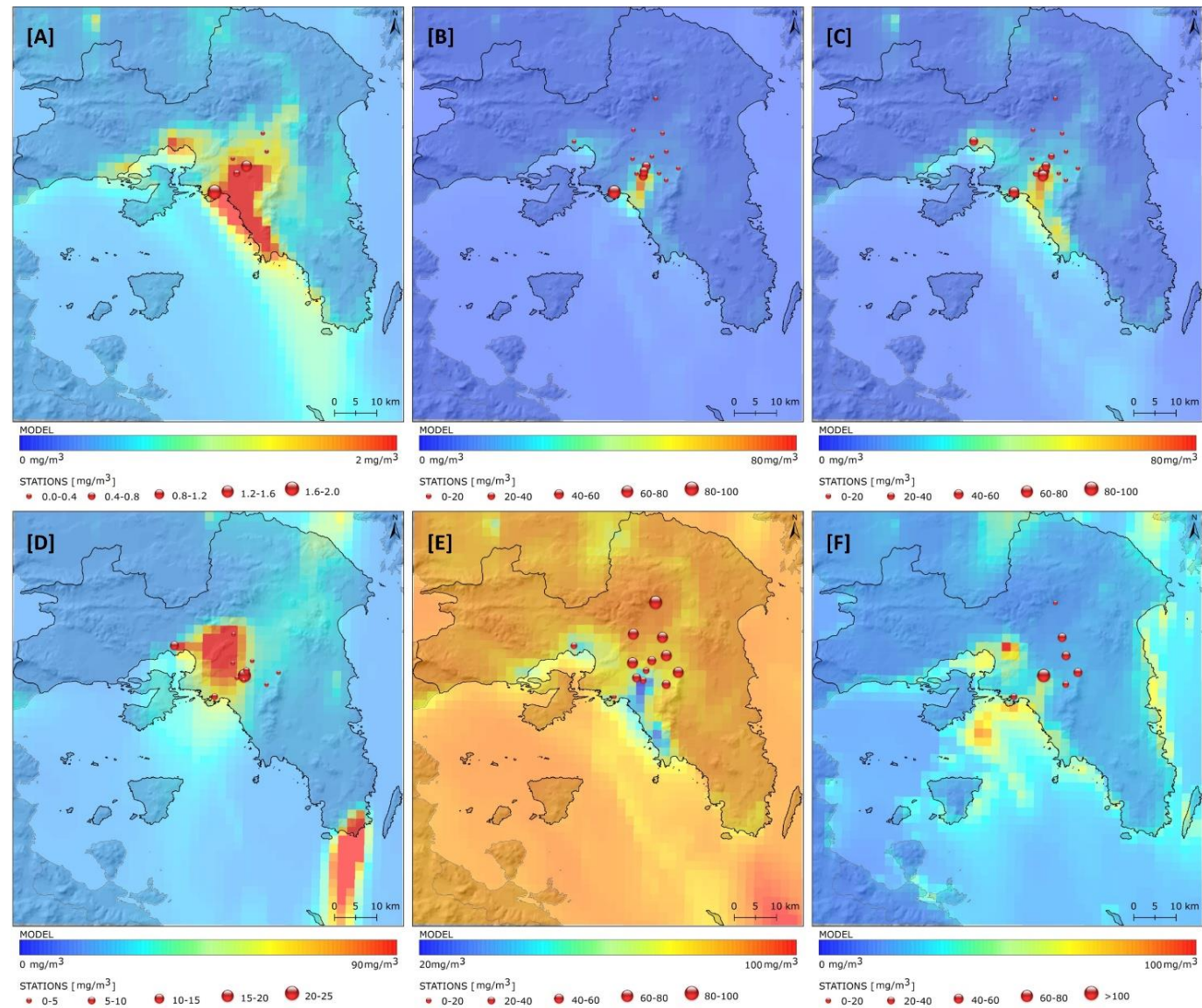

Figure 7. Visualization and spatial distribution of pollutants from both model and stations observations; [A] $\mathrm{CO} ;[\mathrm{B}] \mathrm{NO} ;[\mathrm{C}] \mathrm{NO}_{2} ;[\mathrm{D}] \mathrm{SO}_{2} ;[\mathrm{E}] \mathrm{O}_{3} ;[\mathrm{F}] \mathrm{PM}_{10}$

\section{CONCLUSION}

A GIS based standalone platform has been developed involving programming of ESRI ArcObjects using VBA. Development was motivated by the need of efficient processing of a large amount of ASCII data, as well as lack of generic GIS tools that can be used for massive data processing. The developed platform has been utilized for a case study that required the conversion, analysis, correlation and visualization of air pollutants and meteorological parameters data as derived from observational ground stations and a forecast model. Without this GIS based platform, manually conversion and analysis of such large amount of ASCII data would be tedious, time-consuming and prone to errors. 
The major findings of this research can be summarized in some key points. First, the developed tool greatly reduced time and effort to calculate descriptive statistics for all data in the area of interest and to perform linear regression analysis within a large amount of created raster data. Second, the tool also improved the traceability, reproducibility and transferability of GIS procedures. Moreover, the developed GIS based platform is versatile and can aid in a wide variety of air quality control or environmental management studies with some customizations and improvements. Another key point is that ArcObjects proved to be reliable and flexible tool that lets you to access data in their original format and to build up any analysis tool according the researcher needs. Thereby it reduces the interactive tasks to be programmed using Visual Basic for Applications as a programming language in a user friendly environment. Finally, this versatile programming language allows advanced users to incorporate even more complex formulations for more accurate results.

Nevertheless, further investigation is needed in our case study in order to retrieve more accurate values in terms of spatial and temporal scale. Additional data (even satellite imagery) must be gathered and extend to a decay span of a daily or weekly interval for both ground and forecast model data. Moreover, higher density of stations where it is possible is needed to investigate air pollution variability and explore the effect of other parameters such as elevation and vegetation. The developed platform is flexible for further improvements and adjustments to address any needs and a good start point for future work. In summary, ArcObjects is a key tool for any investigations and environmental studies. It proved to be reliable source especially for studies that handles massive volume of data that requiring complex formulations.

\section{ACKNOWLEDGMENTS}

The authors would like to acknowledge the Greek National Air Pollution Monitoring Network for providing the data and for their valuable assistance to this research.

\section{REFERENCES}

Batelaan, O., \& Smedt, F. De. (2007). GIS-based recharge estimation by coupling surfaceltextendash subsurface water balances. Journal of Hydrology, 337(3-4), 337-355. [Crossref]

Beelen, R., Hoek, G., Pebesma, E., Vienneau, D., de Hoogh, K., \& Briggs, D. J. (2009). Mapping of background air pollution at a fine spatial scale across the European Union. Science of The Total Environment, 407(6), 1852-1867. [Crossref]

Buliung, R. N., \& Kanaroglou, P. S. (2006). A GIS toolkit for exploring geographies of household activity/travel behavior. Journal of Transport Geography, 14(1), 35-51. [Crossref]

Chang, K.-T. (2007). Programming ArcObjects with VBA: A task-oriented approach. CRC Press.

Desideri, U., Arcioni, L., \& Tozzi, M. (2008). Feasibility study for a carbon capture and storage project in northern Italy. International Journal of Energy Research, 32(12), 1175-1183. [Crossref]

Elbir, T. (2004). A GIS based decision support system for estimation, visualization and analysis of air pollution for large Turkish cities. Atmospheric Environment, 38(27), 4509-4517. [Crossref]

Elbir, T., Mangir, N., Kara, M., Simsir, S., Eren, T., \& Ozdemir, S. (2010). Development of a GIS-based decision support system for urban air quality management in the city of Istanbul. Atmospheric Environment, 44(4), 441-454. [Crossref]

España, S., Alcalá, F. J., Vallejos, Á., \& Pulido-Bosch, A. (2011). ArcE: A GIS tool for modelling actual evapotranspiration. Computers \& Geosciences, 37(9), 1468-1475. [Crossref]

España, S., Alcalá, F. J., Vallejos, Á., \& Pulido-Bosch, A. (2013). A GIS tool for modelling annual diffuse infiltration on a plot scale. Computers \& Geosciences, 54, 318-325. [Crossref]

ESRI. (2004). Geoprocessing in ArcGIS. Redlands, CA. [Crossref]

Fameli, K.-M., \& Assimakopoulos, V. D. (2016). The new open Flexible Emission Inventory for Greece and the Greater Athens Area (FEI-GREGAA): Account of pollutant sources and their importance from 2006 to 2012. Atmospheric Environment, 137, 17-37. [Crossref]

Flocas, H., Kelessis, A., Helmis, C., Petrakakis, M., Zoumakis, M., \& Pappas, K. (2009). Synoptic and local scale atmospheric circulation associated with air pollution episodes in an urban Mediterranean area. 
Theoretical and Applied Climatology, 95(3-4), 265-277. [Crossref]

Georgiou, A., \& Skarlatos, D. (2016). Optimal site selection for sitting a solar park using multi-criteria decision analysis and geographical information systems. Geoscientific Instrumentation, Methods and Data Systems, 5(2), 321-332. [Crossref]

Guerreiro, C. B. B., Foltescu, V., \& de Leeuw, F. (2014). Air quality status and trends in Europe. Atmospheric Environment, 98, 376-384. [Crossref]

Henschel, S., Tertre, A. Le, Atkinson, R. W., Querol, X., Pandolfi, M., Zeka, A., ... Goodman, P. G. (2015). Trends of nitrogen oxides in ambient air in nine European cities between 1999 and 2010. Atmospheric Environment, 117, 234-241. [Crossref]

Hirabayashi, S., \& Kroll, C. (2007). Automating regional descriptive statistic computations for environmental modeling. Computers \& Geosciences, 33(4), 457-464. [Crossref]

Kalabokas, P. D., Papayannis, A. D., Tsaknakis, G., \& Ziomas, I. (2012). A study on the atmospheric concentrations of primary and secondary air pollutants in the Athens basin performed by DOAS and DIAL measuring techniques. Science of The Total Environment, 414, 556-563. [Crossref]

Kambezidis, H. D., Weidauer, D., Melas, D., \& Ulbricht, M. (1998). Air quality in the Athens basin during sea breeze and non-sea breeze days using laser-remote-sensing technique. Atmospheric Environment, 32(12), 2173-2182. [Crossref]

Klemm, O., Ziomas, I. C., Balis, D., Suppan, P., Slemr, J., Romero, R., \& Vyras, L. G. (1998). A summer airpollution study in Athens, Greece. Atmospheric Environment, 32(12), 2071-2087. [Crossref]

Mavrakou, T., Philippopoulos, K., \& Deligiorgi, D. (2012). The impact of sea breeze under different synoptic patterns on air pollution within Athens basin. Science of The Total Environment, 433, 31-43. [Crossref]

Papanastasiou, D. K., \& Melas, D. (2009). Climatology and impact on air quality of sea breeze in an urban coastal environment. International Journal of Climatology, 29(2), 305-315. [Crossref]

Qun, Z., Yujin, Y., \& Yuena, K. (2012). GIS Application System Design Applied to Information Monitoring. Physics Procedia, 25, 2235-2241. [Crossref]

Repapis, C., Zerefos, C., \& Tritakis, B. (1977). On the Etesians over the Aegean. In Proc. Acad. Athens (Vol. 52, pp. 572-606).

Righini, G., Cappelletti, A., Ciucci, A., Cremona, G., Piersanti, A., Vitali, L., \& Ciancarella, L. (2014). GIS based assessment of the spatial representativeness of air quality monitoring stations using pollutant emissions data. Atmospheric Environment, 97, 121-129. [Crossref]

Sfetsos, A., \& Vlachogiannis, D. (2013). An analysis of ozone variation in the Greater Athens Area using Granger Causality. Atmospheric Pollution Research, 4(3), 290-297. [Crossref]

Taylor, D. A. (1997). Object technology: a manager's guide. Addison-Wesley Longman Publishing Co., Inc.

Vienneau, D., de Hoogh, K., \& Briggs, D. (2009). A GIS-based method for modelling air pollution exposures across Europe. Science of The Total Environment, 408(2), 255-266. [Crossref]

Wang, S., Leduc, S., Wang, S., Obersteiner, M., Schill, C., \& Koch, B. (2009). A new thinking for renewable energy model: Remote sensing-based renewable energy model. International Journal of Energy Research, 33(8), 778-786. [Crossref]

Xiaodan, W., Xianghao, Z., \& Pan, G. (2010). A GIS-based decision support system for regional eco-security assessment and its application on the Tibetan Plateau. Journal of Environmental Management, 91(10), 1981-1990. [Crossref]

Zeiler, M. (2001). Exploring ArcObjects. Redlands, CA. [Crossref]

Zhan, X., \& Huang, M.-L. (2004). ArcCN-Runoff: an ArcGIS tool for generating curve number and runoff maps. Environmental Modelling \& Software, 19(10), 875-879. [Crossref] 